\title{
System Control Device Electronics Smart Home Using Neural Networks
}

\author{
Safarul Ilham*, Abdul Muin, Dedi Candro \\ Technique Informatics, Universitas Sumatera Utara, Medan, 20155, Indonesia \\ Email: safarulilham@students.usu.ac.id,abdul_muin_nasution@students.usu.ac.id,dedicandroparuliansinaga@students.usu.ac.id
}

A R T I C L E I N F O

Article history:

Received: 15 March, 2017

Accepted: 20 April, 2017

Online: 13 June, 2017

Keywords:

Control System

Smart Home

On-Licryptography

\begin{abstract}
A B S T R A C T
The use of information technology is very useful for today's life and the next, where the human facilitated in doing a variety of activities in the life day to day. By the development of the existing allows people no longer do a job with difficulty. For that, it takes a system safety home using system technology Web-based and complete video streaming CCTV (video streaming) a person can see the condition of his home whenever and wherever by using handphone, laptops and other tools are connected to the Internet network. This tool can facilitate someone in the monitor at home and control equipment the House as open and close and the lock the gate, turning on and off the lights so homeowners are no longer have to visit their home and fear the state of the House because fully security and control in the House was handled by the system. based on the above problems Writer try to design work system a tool that can control the simulation tools home using two Microcontroller is Attiny 2313 and Atmega16.
\end{abstract}

\section{Introduction}

Using of information technology is very useful for today's life and the next, where the human facilitated in doing a variety of activities in the life day to day. With the development of the existing allows people no longer do a job with difficult.

For it takes a system safety home using system technology Web-based and complete video streaming CCTV (video streaming) a person can see the condition of his home whenever and wherever with handphone, laptops and other tools are connected to the Internet network.

This tool can facilitate someone in the monitor the home and control equipment the House as open and close and the lock the gate, turning on and off the lights so homeowners are no longer have to visit his home and fear the state of the House because fully security and control in the House was handled by the system.

Based on the above problems Writer try to design work system a tool that can control the simulation tools home using two microcontroller is ATtiny 2313 and Atmega16.

\section{Research Methodology}

The previous was conducted testing the use of the ability of $\mathrm{NN}$ to receive the input of the sensor Web so that $\mathrm{NN}$, can be decided to do something like that desired. The first test done is

*Corresponding Author: Safarul Ilham, Technique Informatics, Universitas Sumatera Utara, Medan, 20155, Indonesia | safarulilham@students.usu.ac.id using NN as a control the position of a sensor security on an object. Here NN must understand distance sensor door on certain distance with object recipient of the sensor hitch. At the beginning, sensor used is infrared. Testing this fails, because NN can't be receiving put in the form of binary (on/off or detection/not detected). This is because NN only can learn from comparing the mistake of other errors, but with the value should not be too extreme. Testing followed by using the proximity sensor, so that $\mathrm{NN}$ can measure the distance sensor with the Wall. in this test, NN can do a good job.

Testing both performed by trying to use the number of entries for information error that is not the same as the number of the output of NN . Generally NN use the information error with the same amount of the output and reference to NN. From this trial obtained, as long as it can be made a formula that can be used to change the amount of information error that there is a certain number same with the output NN, then it can be used. Of the two experiments this simple tried to design control system motion control home using NN can learn own based on information from some of the sensor to drive the two Motor in order to control the door to move forward and can avoid the theft of people who have not been known by the database.

In general the configuration of the desired is such as in figure 2.1. and figure 2.2. Method used in this study in general use the system is common, that NN with learning Backpropagation. Two or sub-system added the counter error and braking, therefore, in 


\section{S. Ilham et al. / Advances in Science, Technology and Engineering Systems Journal Vol. 2, No. 5, 35-37 (2017)}

the discussion next will not shown formulaformula, except for the counter error and braking, as well as an explanation system configuration made. rest (for example of $\mathrm{NN}$ ) has been much discussed in the book text as in the Freeman (1992) or other reference. For sensor, pre-process, drivers, Motor, mechanical will not discussed here, because it depends on the type used or depending needs. That will be discussed here just a mechanism to a control home appliance can have the ability to move to close and open the door by itself through the process of learning themselves without guide from outside or learning process previous off-line.

Configuration mechanical equipment Figure 1. explain the form of mechanical equipment and Figure 2. shows configuration control system using NN and the process of learning on-line.
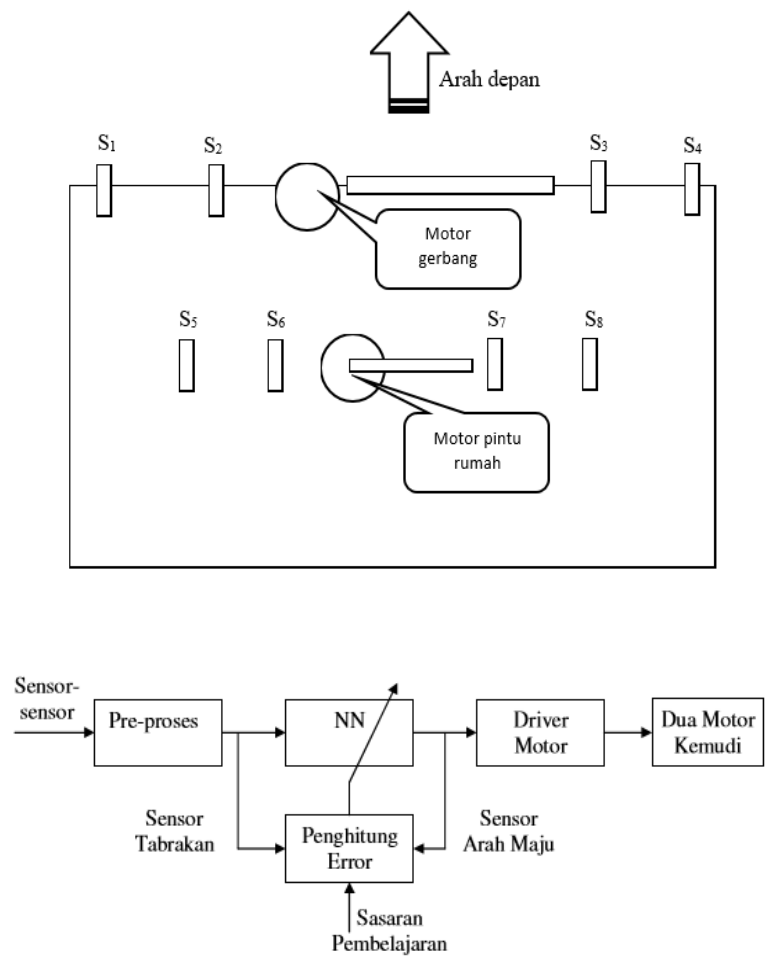

Figure 2. System Configuration

\subsection{Architecture NN to controller}

In this experiment used $\mathrm{NN}$ configuration 10 neurons in the input layer to read 8 sensor collision and two speed sensor, some (10 to 20 ) neurons in the hidden layer and 2 neurons in the output layer to run the Motor the left and Motor right.

Sensor collision is proximity sensor used to measure the distance objects that exist in front of the sensor. This sensor planned have a range of 0 to 25 centimeters. While the speed sensor is used to determine the amount of Motor speed at that time including forward or backward. Pre-process is used only for the condition the output of the sensor collision and speed sensor to fit the input of NN the value of 0 to 1 .

The key of this system is a model or formulas that exist in the counter error. In the model $\mathrm{NN}$, the number of error entered or will be used in the process of learning is the same as the number of neurons output. Where error mean error output of $\mathrm{NN}$ to reference value. but in this system, not at all used or no data or www.astesi.com reference value given. of course this will make it difficult for learning process NN. The only information that can be used for the learning process is input a number of 10 that point, the actual input is not suitable for error from both sides of the relationship or number of input. Counter error is considered as a major determinant because he should be able to change or calculate than 10 input into 2 data errors can then be used for the learning process NN. Given no relationship direct mathematical between input and error, then made approach functional (operational), that if a sensor has a particular value or detect certain conditions, then are to blame is the Motor next to where. Approach simple this can be made formula a very simple of counter error and even the form of formulas can also be created, as long as it meets the approaches that have been used.

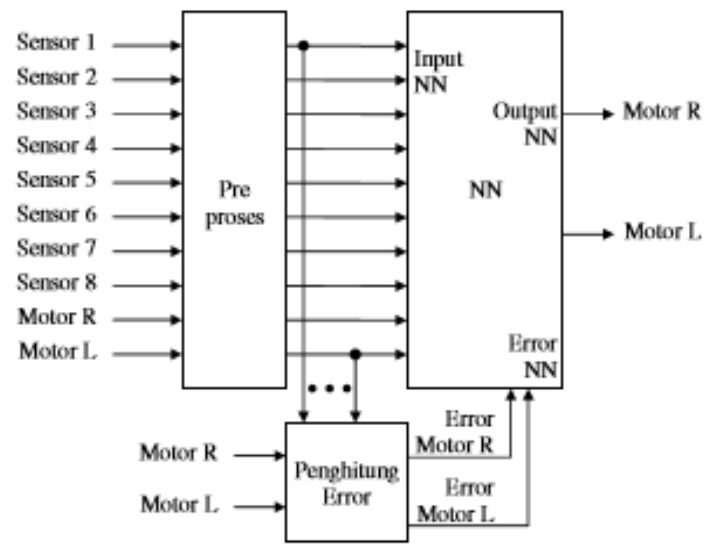

Figure 3. Architecture NN to control system

$\mathrm{eL}=(-\mathrm{S} 1-\mathrm{S} 2+\mathrm{S} 7+\mathrm{S} 6+\mathrm{S} 5+\mathrm{sML})$

$\mathrm{eR}=(-\mathrm{S} 1-\mathrm{S} 8+\mathrm{S} 3+\mathrm{S} 4+\mathrm{S} 5+\mathrm{sMR})(1)$

or

$\mathrm{eL}=(-\mathrm{S} 1-\mathrm{S} 2+\mathrm{S} 7+\mathrm{S} 6+\mathrm{S} 5+\mathrm{sML})+(\mathrm{Rnd} * 0.5-0.25)$

$\mathrm{eR}=(-\mathrm{S} 1-\mathrm{S} 8+\mathrm{S} 3+\mathrm{S} 4+\mathrm{S} 5+\mathrm{sMR})+(\mathrm{Rnd} * 0.5-0.25)$

where:

- $\quad \mathrm{eL}$ and $\mathrm{eR}$ is error output counter error for learning process NN

- $\quad \mathrm{S} 1$ to $\mathrm{S} 8$ is output proximity sensor after through the preprocess

- $\quad$ SML and sMR is output speed sensor after through the preprocess

Formula (1) is the simplest form to determine the error motion of the Motor, while the formula (2) added functionality random to get the possibility of movement vary. Or can be used other forms.

\section{Results and Discussions}

After all the design of hardware and software is completed, the next step is testing Circuit has been designed. This test function to show the error writers do when connecting the program is made with a series of which has been designed for each design designed controlled by the system program previously have been made to run the system digital. 


\subsection{Test Series USB4REL}

Serves as a communication between Computers with Devices, and continue execution to atmega16.

Testing in a series of USB4REL this can be done by connecting a series of minimum attinny 2313 with adapter power supply as a source voltage. Feet 20 th connected by voltage source DC $5 \mathrm{~V}$, while the foot of 10 th connected to the ground.

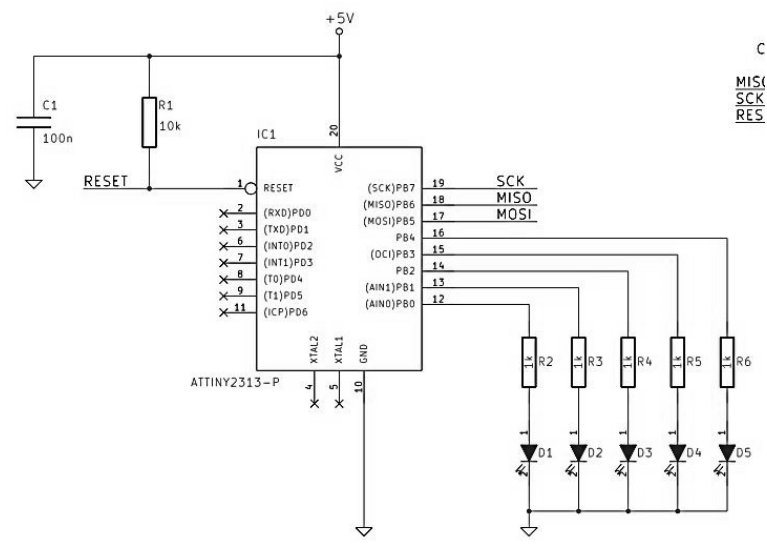

Figure 3 Series USB4REL

Testing program

\#include $<$ delay.h $>$

void main(void)

\{

while (1)

\{

// Place your code here

if $(\mathrm{PIND}==0 \mathrm{xf0})$

$\{$ PORTB $=0 x f f ;\}$

\}

\}

\section{Conclusions and Suggestions}

\subsection{Conclusions}

The observations made during the study author can draw conclusions:

1. Home security systems can monitor through Video Systems Live Streaming and controlled in a Web interface using simulation.

2. Using the Web systems, users do not need to install the application in the device controller, the user can also access system using laptop or smartphone connected with the Internet network.

\subsection{Suggestions}

From observations the authors did, there are some things that can be developed back namely:

1. From the results of the design, manufacture and trial security systems this, it would be a maximum if this system developed back to be able to activate the home appliance other such as water pump, shutters, and air conditioning.

2. Video facilities that exist in the system only limited to live streaming, so the camera Web Cam not record and can not be replay, it would be a maximum if the Web Cam available can also record.

\section{References}

[1] Adhi Prasetio, Web Design Beginners, PT Mediakita, Jakarta, 2010,

[2] Andi, Build-Based Applications PHP and MySQL, 2nd Edition, Andi offset, Yogyakarta, 2012,

[3] Anhar, PHP \& SQL in Self-Taught, PT Mediakita, Jakarta, 2010,

[4] Heri andrianto, Programming AVR Micro controller Atmega16, PT Informatika, Bandung, 2013,

[5] Harmein, Bolton, W, Irzam Harmein, Programable Logic Controller (PLC), Edition 3, Irzam Harmein, PT Gelora Aksara Pratama, Jakarta, 2011.

[6] Muchlas, Digital Circuits, PT Gaya Media, Yogyakarta2013.

[7] Prawiroredjo Kiki, Robot Delivery Auto-Based AVR Microcontroller Atmega16., Journal of electronics. Lecturer Department of Electrical Engineering-FTI, Trisakti University, 2010.

[8] Taufik DWI Septian Suyadhian, The Microcontroller As a Computer System or Microcomputers Single Chip, Edition-1, 406, Gramedia, Jakarta, 2010.

[9] Toni Kun, Website Advanced Design With JQuery, PT Mediakita, Jakarta, 2010.

[10] Rides computers, My SQL Database Server, PT Mediakita, Jakarta, 2010.

[11] Widodo Budiharto, S.Si., Digital Electronics + Microprocessors, Publisher Andi, Yogyakarta, 2010.

[12] Zul Bahrum C, Applications Microcontroller System For Parking, Journal Gradient 3 (1): 200-203, January 2013. 